\title{
Analysis and Classification of Noise Sources of Conveyor Systems by Sound Visualizing on the Postal Package Sorting Line
}

\author{
Pavol Liptai ${ }^{1 *}$, Ervin Lumnitzer ${ }^{1}$, Marek Moravec ${ }^{1}$, Miriama Piňosová ${ }^{1}$ \\ 1 The Technical University of Košice, Faculty of Materials, Metallurgy and Recycling, Letná 9, Košice, Slovakia \\ * Corresponding author's e-mail: pavol.liptai@tuke.sk
}

\begin{abstract}
Sound visualization tools are now widely used in industry. As a tool, acoustic cameras are also well- suited for faster identification of errors as well as individual states while operating devices. The aim of this paper was to locate and quantify noise sources on a packet sorting line using an acoustic camera and then to propose noise reduction measures. Localization of noise sources was performed by means of an acoustic camera with a microphone ring array. The result of these measurements and analyses was to sort the individual noise sources from less noisy to the noisiest, which gives a good assumption for better planning of spending on the implementation of noise reduction measures. The outputs of these measurements also give information on the character and frequency composition of the sound of individual sources, which will help out in the design of specific noise measures.
\end{abstract}

Keywords: noise sources, sound visualization, noise location, conveyor systems.

\section{INTRODUCTION}

Belt conveyors in automated facilities, which are used in production lines, during sorting of postal items, or on airports, are specific and diverse [1]. Reliable operation of these types of equipment is a key factor in the efficient operation of company logistics [2]. Several ways of monitoring belt conveyors are described in the publications [3, 4]. Monitoring, from the point of view of its execution, is quite a difficult process. The difficulty lies in the need of monitoring several parameters which can be really complicated due to the length of the transport route and volume of the monitored data $[5 \div 7]$. The issues of online monitoring of belt conveyor were also described by Molnár et al. [8]. Within their research, benchmarking and evaluation standards, which support decision making processes in online monitoring, were considered.

Monitoring and evaluating operation modes are needed from the point of view of obtaining device status information as well as predicting failures that may occur. Currently, the methods which can be used to monitor and diagnose conveyor belts involve acoustic visualization. The advantage of these methods is the ability to monitor the devices remotely without any interference in them, sensor mounting, etc.

Before proposing technical measures to reduce noise from machinery and equipment, it is necessary to know the frequency spectrum components of the sound. Currently, acoustic visualization techniques are clearly one of the ways to obtain relevant machines and equipment status data. Döbler and Heilmann [9] discussed the perspective of using acoustic cameras. Acoustic cameras that work on the Beamforming principle, as well as concepts, techniques, and problems associated with their use are described in works $[10 \div 12]$.

Another important step for obtaining information from the data measured through acoustic cameras is the correct analysis of individual com- 
ponents of mechanical and electrical equipment. Such analyses use the various approaches and methods discussed in the publications $[13 \div 22]$.

\section{MATERIALS AND METHODS}

The workplace of the post where the measurements were carried out is aimed at sorting postal items. A specific description of the workplace is described in the article [23], which was mentioned in the previous issue of the journal and preceded this experiment. The acoustic camera which consists ring antenna with 48 microphones and camera was used for the realization of the measurements. This acoustic camera works on the beamforming principle, which is a signal processing technique used in sensor arrays for direc- tional signal transmission or reception. The simplest beamforming architecture is described the Delay-Sum and is illustrated in Fig. 1. Measurement time record was set at 8 seconds. Data analysis was realized with the NoiseImage program that is designed for processing of measured data. The outputs were generated as time sound record, spectrum, spectrogram, and sound images.

\section{RESULTS AND DISCUSSION}

The measured audio records of selected devices were corrected by the weighting filter A; frequency spectrum and acoustic images were subsequently generated in the NoiseImage software.

Fig. 2 shows the acoustic image of the sorting line scanner. Fig. 3 presents the A-weighted fre-
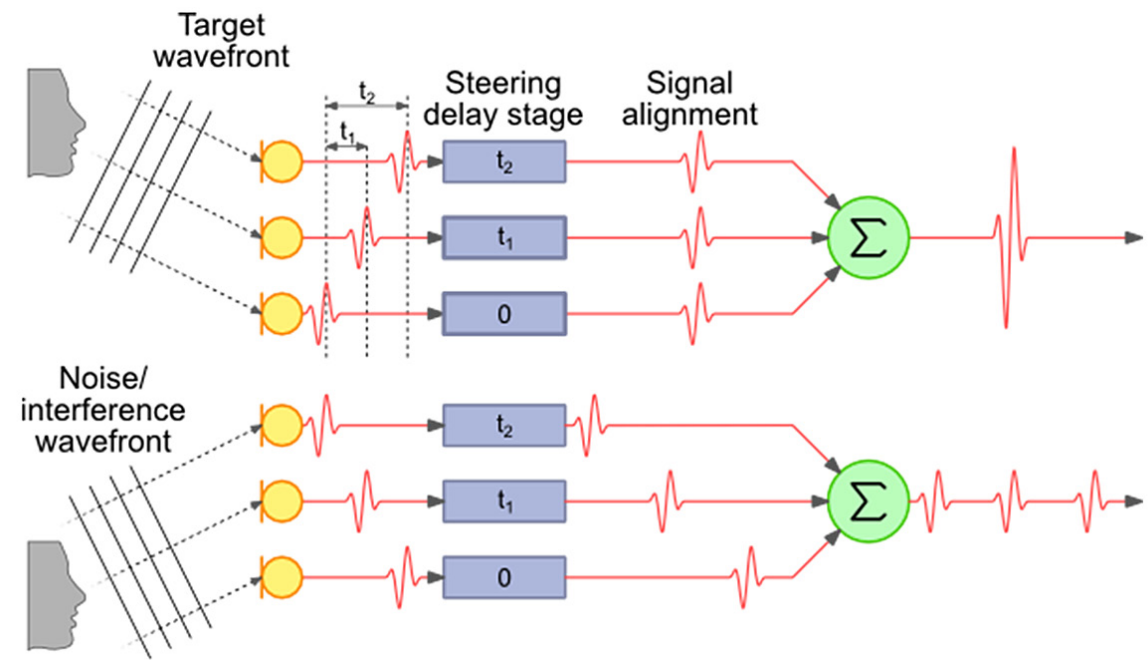

Fig. 1. Delay-Sum architecture [24]

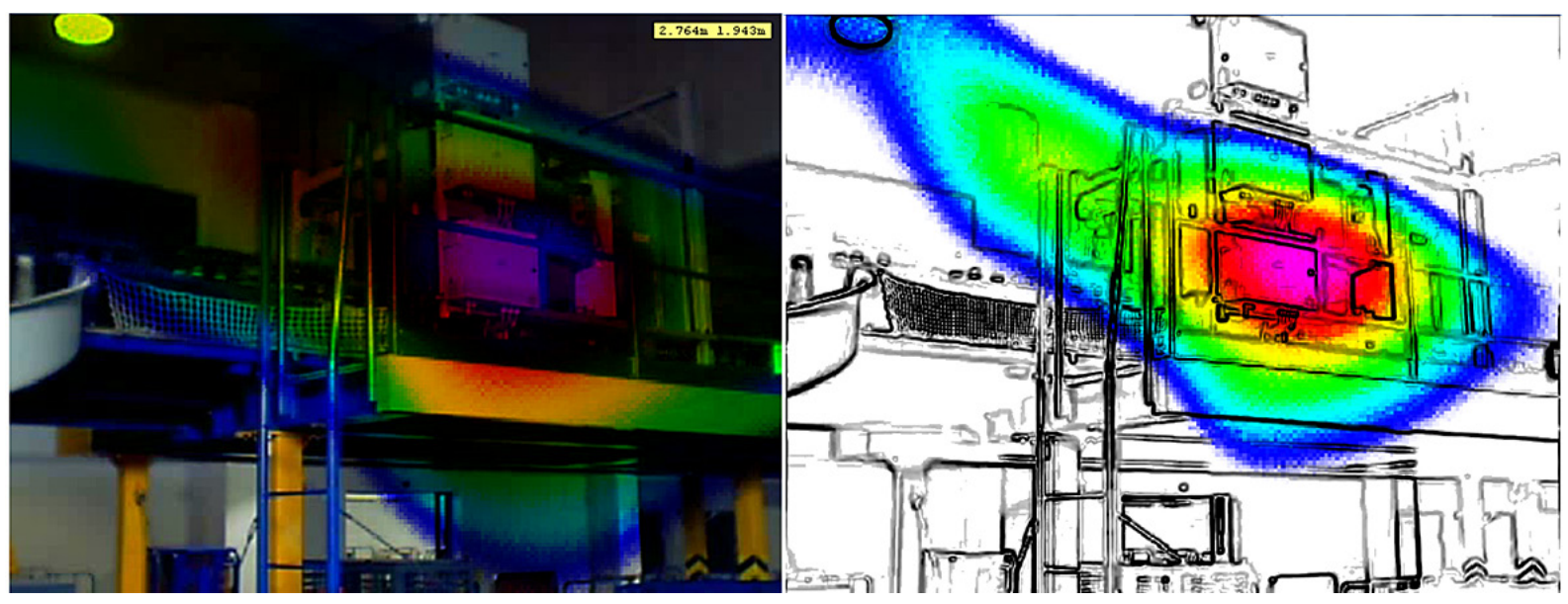

Fig. 2. The acoustic image with localization of the prevailing sound source 


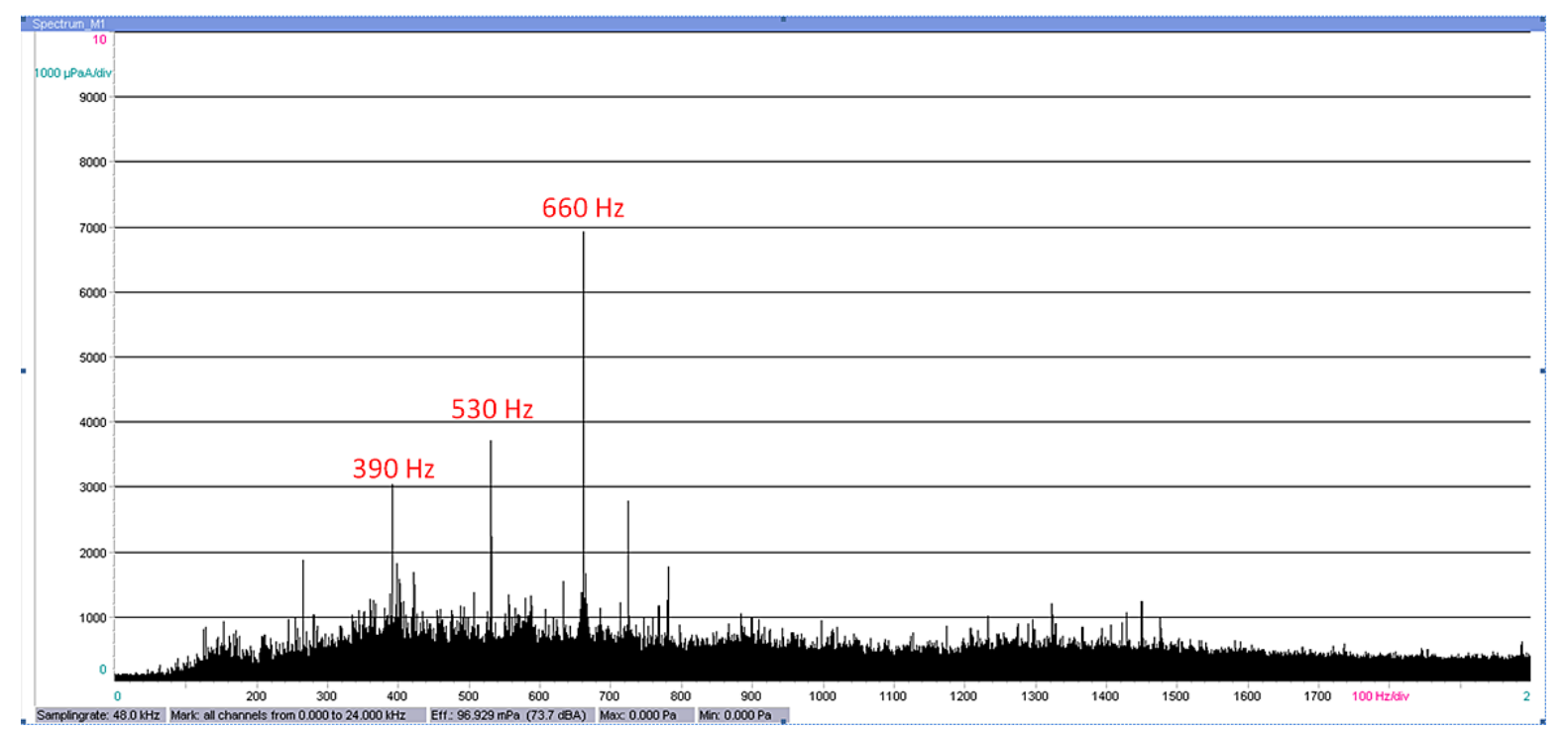

Fig. 3. A-weighted frequency spectrum

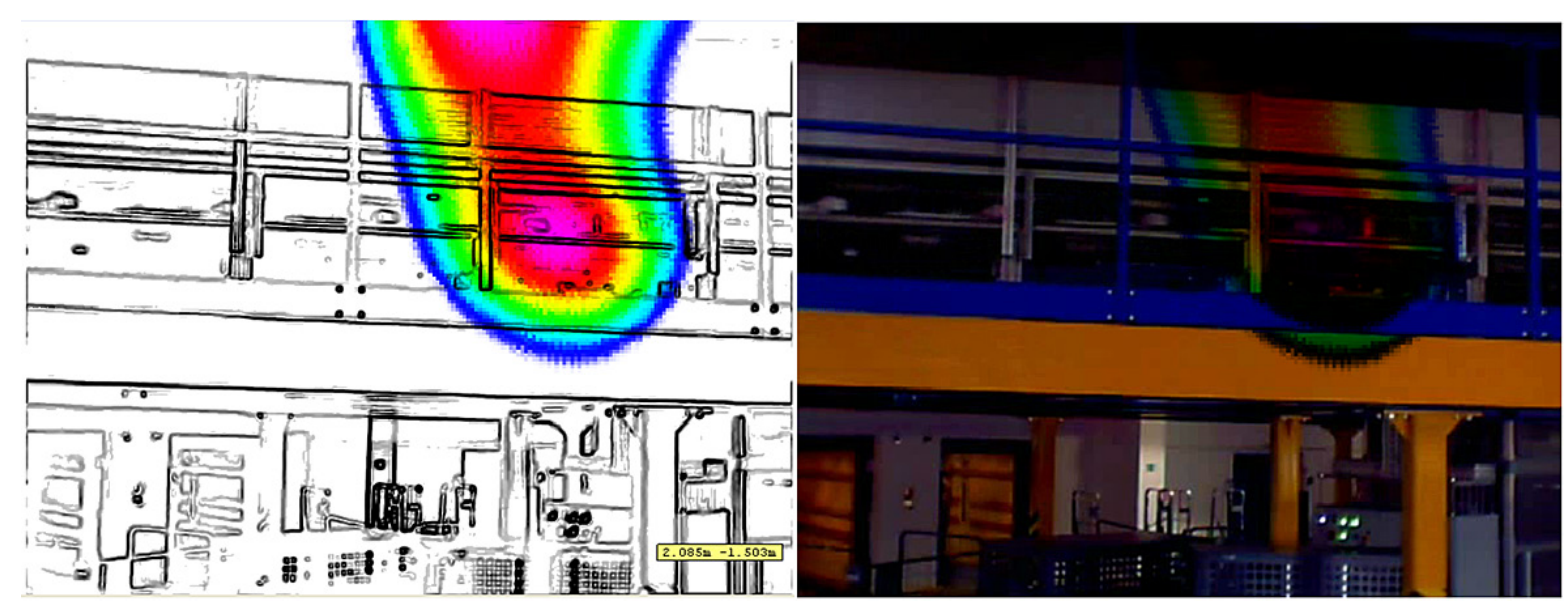

Fig. 4. The acoustic image with localization of the prevailing sound source

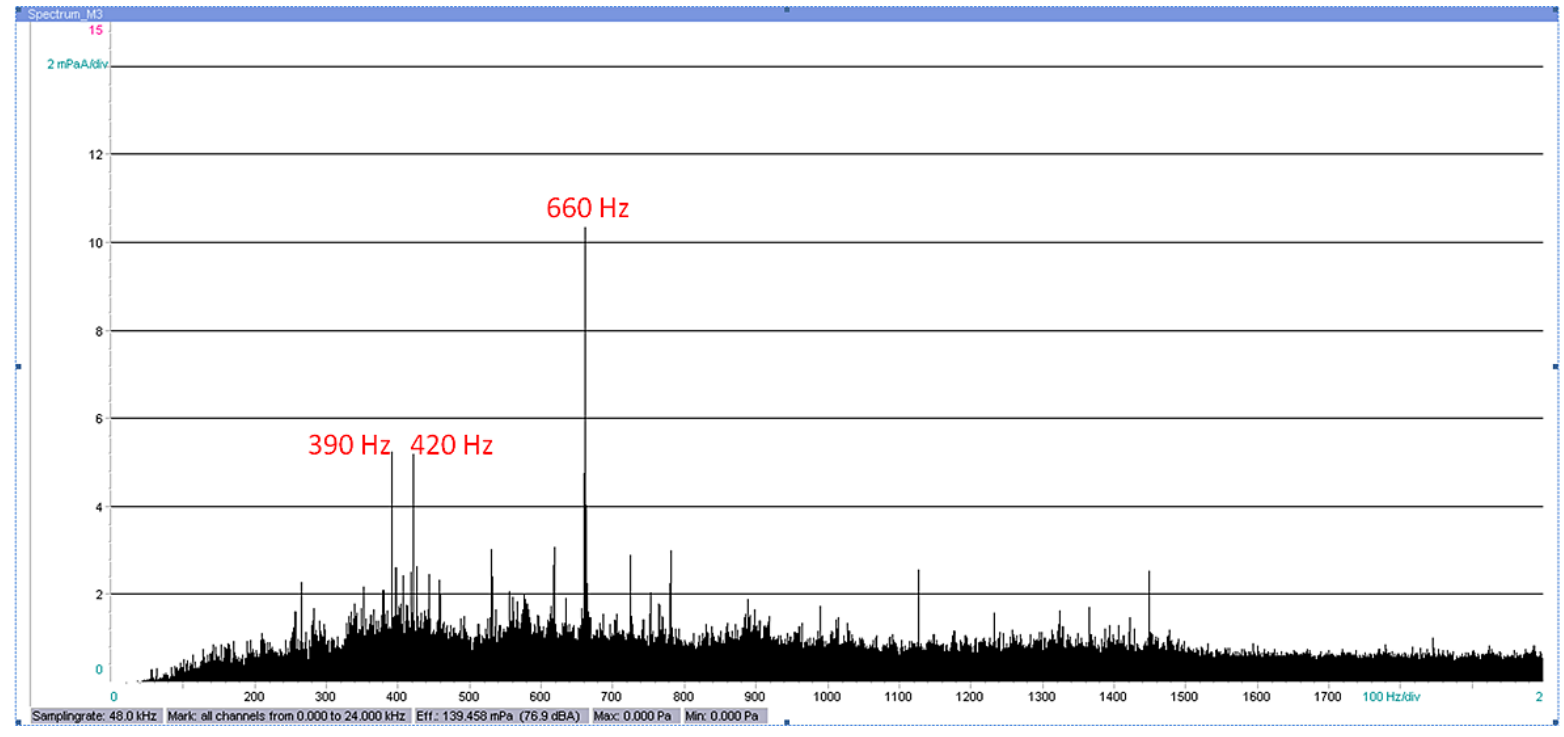

Fig. 5. A-weighted frequency spectrum 


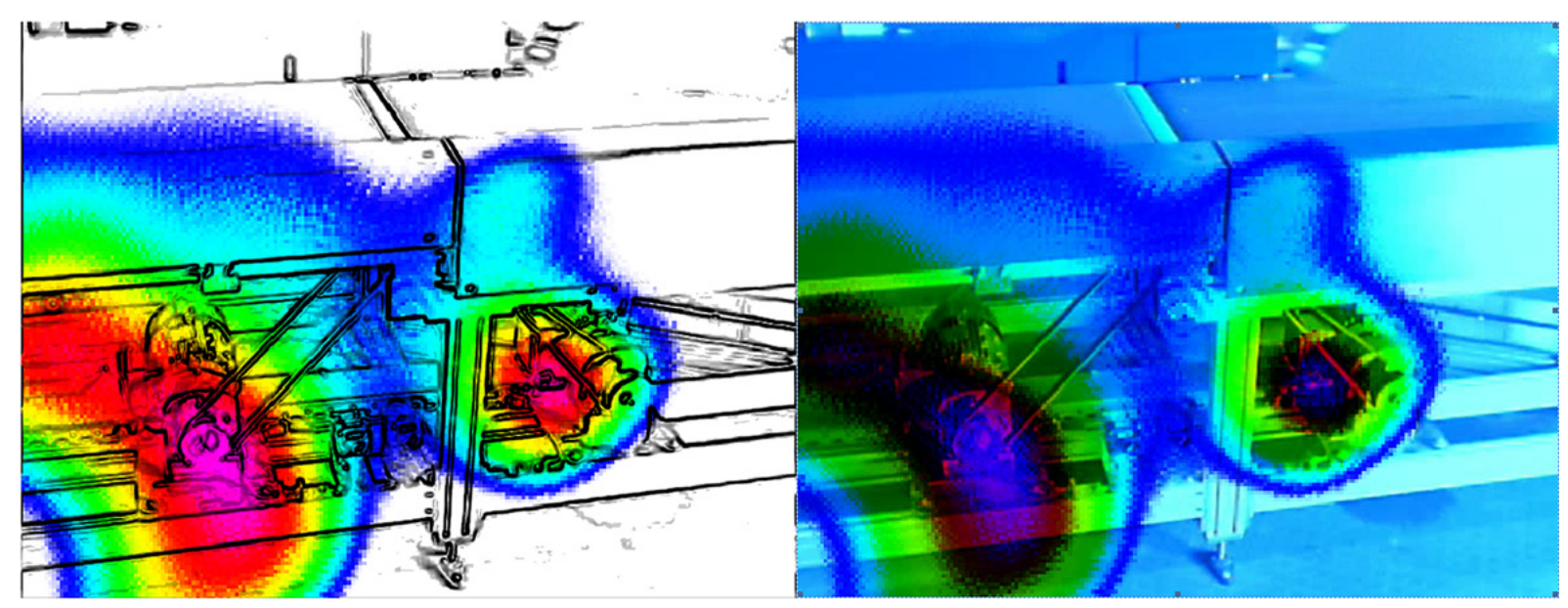

Fig. 6. The acoustic image with localization of the prevailing sound source

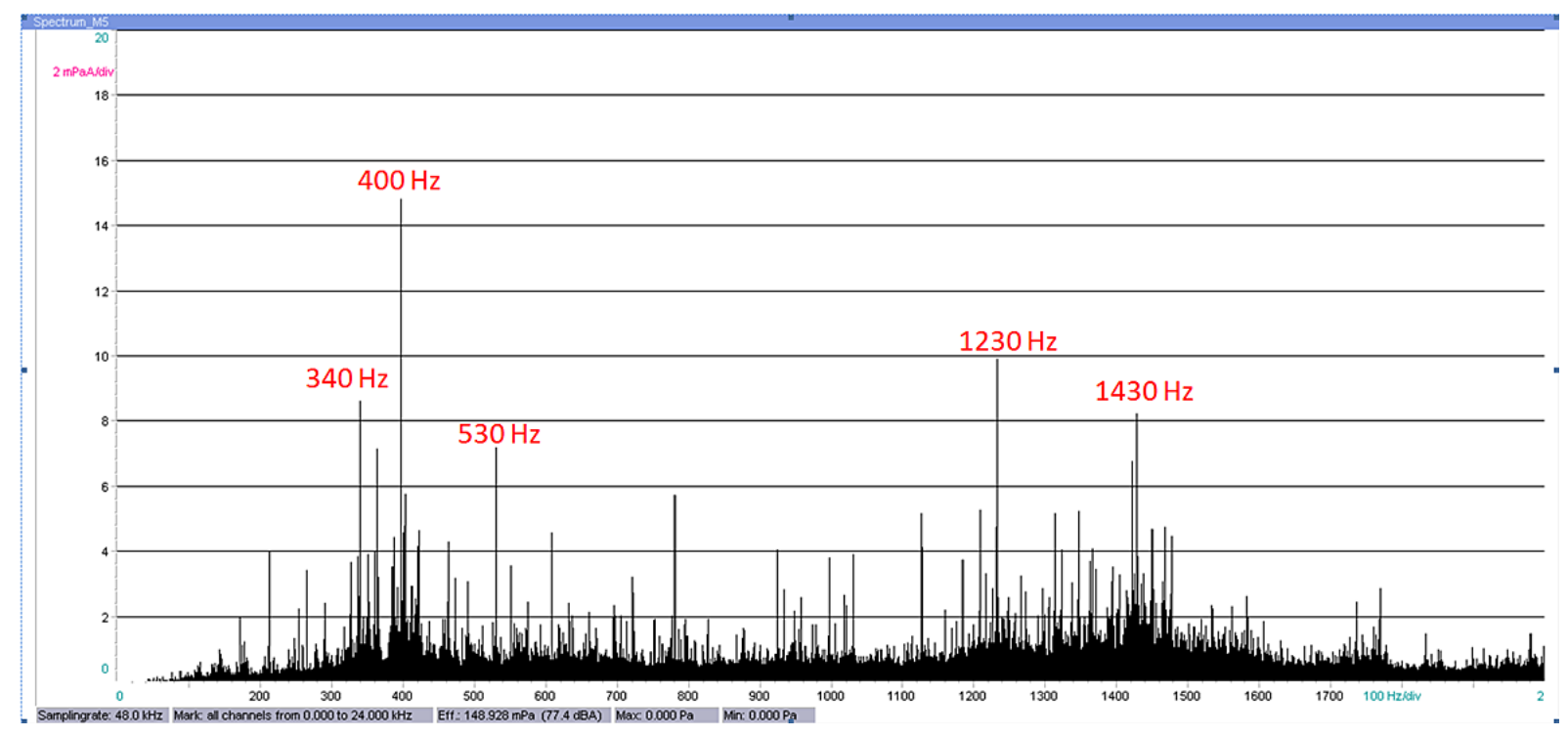

Fig. 7. A-weighted frequency spectrum

quency spectrum. From the resulting frequency spectrum, the sound character of the recorded device with its typical frequencies, namely $390 \mathrm{~Hz}$, $530 \mathrm{~Hz}$, and $660 \mathrm{~Hz}$, can be seen.

Fig. 4 shows the acoustic image of the emitting noise of an electric motor with chain drive which serves to drive the transport tubs of the sorting line. Fig. 5 presents the A-weighted frequency spectrum. From the resulting frequency spectrum, the sound character of the recorded device with its typical frequencies, namely $390 \mathrm{~Hz}$, $420 \mathrm{~Hz}$, and $660 \mathrm{~Hz}$, can be seen.

Fig. 6 depicts an acoustic image of the emitted noise by an electric motor with a wedge belt which serves to drive the conveyor belt of the sorting line. Fig. 7 shows the A-weighted frequency spectrum. From the resulting frequency spectrum, the sound character of the recorded device with its typical frequencies, namely $340 \mathrm{~Hz}, 400 \mathrm{~Hz}, 530$ $\mathrm{Hz}, 1230 \mathrm{~Hz}$, and $1430 \mathrm{~Hz}$, can be seen.

\section{CONCLUSIONS}

The presented work was focused on the solution of noise sources in the working environment. From the point of view of reducing noise at the specific post workplace, it is necessary to focus mainly on the dominant sources of noise, in this case - the electric drives and their transmissions. Appropriate ways of reducing the noise levels in the workplace can be described as follows: 
- targeted and repeated maintenance of the drive components,

- partial or full coverage of devices with access during repairs, maintenance, and revisions.

Other possibilities are to introduce regular vibroacoustic measurements in order to quickly identify the undesirable phenomena and machine and device failures, followed by a report on the status of the device. In addition, it is suitable for future planning of funds for the maintenance or replacement of machinery and device.

\section{Acknowledgements}

This paper was written in the frame of the work on the projects KEGA 032TUKE-4/2018 (100\%).

\section{REFERENCES}

1. Mikusova N., Millo S. Modelling conveyor belt passage with a driving drum using finite element methods. Adv Sci Technol Res J., 11(4), 2017, 239-246.

2. Surtees A.J. Conveyor system commissioning, maintenance and failure analysis using black box techniques. Bulk Solids Handl., 16, 1996, 209-216.

3. Wang S., Guo W., Wen W., Chen R., Li T., Fang F. Research on Belt Conveyor Monitoring and Control System. Inf. Comput. Appl. SE., 44, 2011, 334-339.

4. Lu Q., Wang X., Zhuang L. Research and Design of Monitoring System for Belt Conveyor. Int. Conf. Comput. Sci. Serv. Syst., IEEE., 2012, 1943-1945.

5. Wang S., Guo W., Wen W. Based On the LM3S8962 MCU Belt Conveyor monitoring System. 2010 ETP/IITA Conf. Syst. Sci. Simul. Eng. (SSSE 2010), ETP-Engineering Technology Press, Kowloon, 2010, 303-305.

6. Debski H., Teter A., Kubiak T., Samborski S. Local buckling, post-buckling and collapse of thinwalled channel section composite columns subjected to quasi-static compression. Compos Struct., 136, 2016, 593-601.

7. Garbacz T., Jachowicz T., Gajdoš I., Kijewski G. Research on the influence of blowing agent on selected properties of extruded cellular products. Adv Sci Technol Res J. 9(28), 2015, 81-88.

8. Molnár V., Fedorko G., Andrejiová M., Grinčová A., Michalik P. Online monitoring of a pipe conveyor. Part I: Measurement and analysis of selected operational parameters. Meas., J. Int. Meas. Confed., 94, 2016, 364-371.

9. Döbler D., Heilmann G. Perspectives of the Acoustic Camera. In: Environmental Noise Control. The 2005 Congress and Exposition on Noise Control Engineering, 2015, 1-9.
10. Fischer S., Simmer K.U. Beamforming microphone arrays for speech acquisition in noisy environments. Speech Commun., 20(3-4), 1996, 215-227.

11. Johnson D.H., Dudgeon D.E. Array signal processing: concepts and techniques. 1992, $533 \mathrm{p}$.

12. Gauthier P.A., Camier C., Pasco Y., Berry A., Chambatte E., Lapointe R. et al. Beamforming regularization matrix and inverse problems applied to sound field measurement and extrapolation using microphone array. Journal of Sound and Vibration. 330, 2011, 5852-5877.

13. Urbanek J., Barszcz T., Zimroz R., Antoni J. Application of averaged instantaneous power spectrum for diagnostics of machinery operating under nonstationary operational conditions. Meas J Int Meas Confed., 45(7), 2012, 1782-1791.

14. Opocenska H., Hammer M. Use of technical diagnostics in predictive maintenance. In: 17th International Conference on Mechatronics - Mechatronika (ME). 2016, 1-6.

15. Dolnik B. Contribution to analysis of daily diagram of supply voltage in low voltage network: Working days versus non-working days. In: Proceedings of the 2015 16th International Scientific Conference on Electric Power Engineering. EPE 2015, VŠBTU, 2015, 373-376.

16. Hunady R., Hagara M. A new procedure of modal parameter estimation for high-speed digital image correlation. Mech Syst Signal Process., 93, 2017, 66-79.

17. Trebuna F., Hunady R., Bobovsky Z., Hagara M. Results and Experiences from the Application of Digital Image Correlation in Operational Modal Analysis. ACTA Polytech Hungarica., 10(5), 2013, 159-174.

18. Marton M., Ovsenik L., Huszanik T., Spes M. Analysis of possibilities for measurement effect of visibility in experimental FSO system. OPEN Comput Sci., 8(1), 2018, 135-141.

19. Ivaniga P., Ivaniga T. Comparison of DPSK and RZDPSK Modulations in Optical Channel with Speed of 10 Gbps. J Inf Organ Sci., 41(2), 2017, 185-196.

20. Grega R., Krajňák J., Žulová L. et al. Failure analysis of driveshaft of truck body caused by vibrations. Engineering Failure Analysis, 79, 2017, 208-215.

21. Nieszporek T., Boral P., Golebski R. An analysis of gearing. 4th International Conference on Computing and Solutions in Manufacturing Engineering (CoSME), 94, 2017.

22. Golebski R., Ivandic Z. Analysis of Modification of Spur Gear Profile. Tehnicki Vjesnik-Technical Gazette, 25(2), 2018, 643-648.

23. Piňosová M., Andrejiová M., Liptai P., Lumnitzer E. Objective and subjective evaluation of the risk physical factors near to conveyor system. Adv Sci Technol Res J., 12(3), 2018.

24. Delay Sum Beamforming - The Lab Book Pages, (http://www.labbookpages.co.uk). 